\title{
CALCIUM OXALATE CRYSTALS IN LEAVES OF QUERCUS CERRIS L. AND Q. ILEX L.
}

\author{
Hatice ÇölgeÇen, Ayşe Kaplan and H. Nurhan BüyükKartal ${ }^{1}$ \\ Zonguldak Karaelmas Üniversitesi, Fen-Edebiyat Fakültesi, \\ Biyoloji Bölümü 67100 Incivez /Zonguldak, Turkey \\ haticecolgecen@hotmail.com,aysekaplan2003@hotmail.com
}

Key words: Quercus, Calcium oxalate crystals, Leaf anatomy

\begin{abstract}
Leaves of Quercus cerris L. were collected from Zonguldak, Devrek and those of Q. ilex L. samples were collected from Zonguldak, Ereğli, Turkey. The leaf sections were subjected to histochemical analysis and brown-black stained calcium oxalate crystals were identified. The organic contents in the leaves were completely cleaned for polarizing microscope investigation. Calcium oxalate crystals were found to be druz and prismatic in $Q$. cerris and $Q$. ilex species. While druz crystals were localized in mesophyll, prismatic ones were localized around the leaf vessels. The amount of calcium oxalate crystals per $\mathrm{mm}^{2}$ was determined in permanent preparations.
\end{abstract}

Oxalic acid is produced by a variety of plants and animals and can exist in the cell, either as soluble $\mathrm{Na}$ and $\mathrm{K}$ salts or as calcium oxalate, an insoluble crystal. Calcium oxalate crystals are formed as a result of the bonding of calcium ions with metabolically formed oxalate ions. The crystal form of calcium oxalate in human and animal cells are generally seen outside the cell and display pathological features. The best example for this is the kidney stones. Unlike those in human and animal tissues, the calcium oxalate crystals in plants are not pathological. The calcium oxalate crystals in plants ensure calcium storage and as a defense mechanism against animals. They can be very useful in one or more phases of the life cycle of a plant. The crystal form of calcium oxalate is extensively seen in higher plants. It is either very scarce or non-existent in some plant families. Discovering that those crystals can be utilized in systematic studies, there has been an increase in their studies recently.

Quercus, belonging to Fagaceae family, is one of the important forest trees of Turkey. Two Quercus species, namely Q. cerris L. and Q. ilex L. were studied by Kartal and Kaplan (2005) with respect to leaf and stem anatomy and pollen morphology. However, there is no study on these species concerning calcium oxalate crystals.

Q. cerris samples were collected from Zonguldak, Devrek and Q. ilex samples were collected from Zonguldak, Ereğli, Turkey. The samples were taken from one year old shoots of same age trees. Leaf samples were put in FAA fixing and preservation solution. Yasue technique (Yasue 1969) was applied to the superficial leaf sections for the histochemical determination of calcium oxalate. After the identification of calcium oxalate, the leaves were subjected to clearing process by using $\mathrm{NaOCl}$ (Frank 1972). Following the dehydration process by alcohol series, the leaves were put in pure xylol and permanent preparations were made by Canada balsam. The leaves were investigated by using Reichert Polarizing microscope, color photos were taken and the shape and location of calcium oxalate crystals were determined.

Histochemically brown-black stained calcium oxalate crystals were identified in both $Q$. cerris and $Q$. ilex species. After clearing, the permanent preparations were investigated by polarizing microscope, and calcium oxalate crystals were found to be in druz and prismatic forms in $Q$. cerris and $Q$. ilex species. While druz crystals were localized in mesophyll, prismatic ones were

\footnotetext{
${ }^{1}$ Ankara Üniversitesi, Fen Fakültesi, Biyoloji Bölümü 06100 Tandoğan/Ankara, Turkey.

E-mail: bkartal@science.ankara.edu.tr
} 

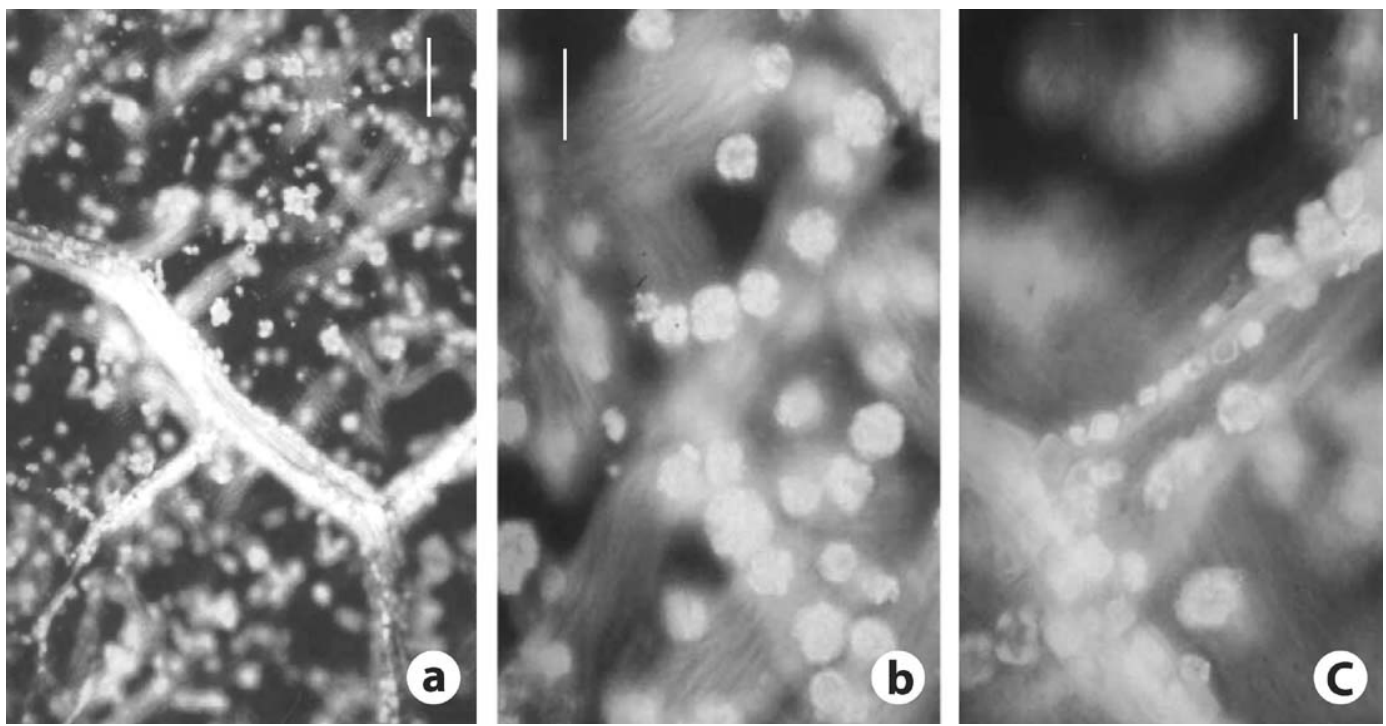

Fig. 1. Calcium oxalate crystals in $Q$. cerris leaves (Bars: $\mathrm{a}=50 \mu \mathrm{m}, \mathrm{b}, \mathrm{c}=20 \mu \mathrm{m}$ ).
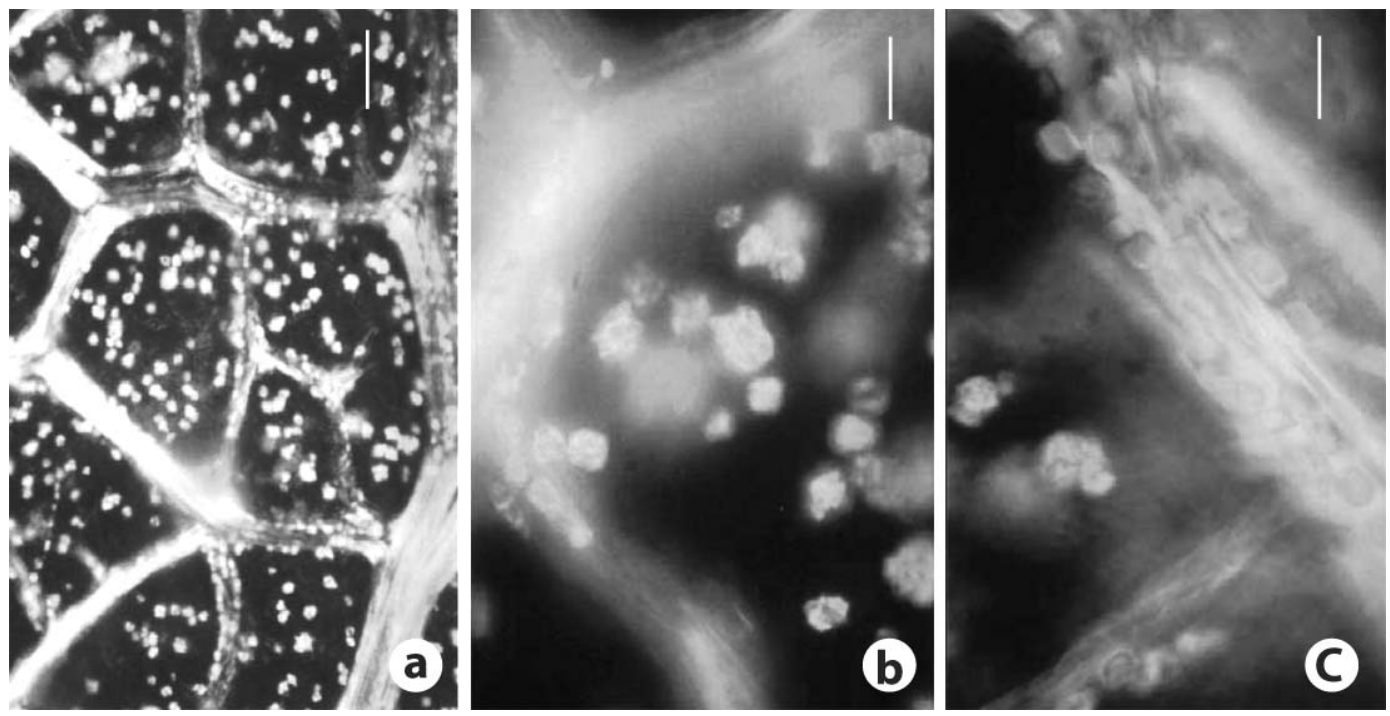

Fig. 2. Calcium oxalate crystals in $Q$. ilex leaves (Bars: $\mathrm{a}=50 \mu \mathrm{m}, \mathrm{b}, \mathrm{c}=20 \mu \mathrm{m}$ ).

localized around the vessels of leaves (Figs. 1-2). Crystals were counted and photographed by polarizing microscope. An average of $383.2 \pm 2.2 / \mathrm{mm}^{2}$ druz crystal was counted in mesophyll in Q. cerris. In the vessels, an average of $371.4 \pm 2.6 / \mathrm{mm}^{2}$ prismatic crystal was counted. An average of $223.1 \pm 1.8 / \mathrm{mm}^{2}$ druz crystal was identified in mesophyll in $Q$. ilex. In the vessels, an average of $406.6 \pm 1.9 / \mathrm{mm}^{2}$ prismatic crystal was counted. While the mesophyll of $Q$. cerris has almost twice as many druz crystals than the mesophyll of $Q$. ilex, the situation is the opposite for the vessels since $Q$. ilex has a greater number of prismatic crystals than $Q$. cerris. By discovering that crystals can be considered as the distinctive features among species, interest on this topic have increased recently (Tian et al. 1998, Lersten and Horner 2000). 


\section{References}

Frank, E. 1972. The formation of crystals idioblasts in Canavalia ensiformis D.C. at different levels of calcium supply. Z. Pflanzenphysiol. 67: 350-358.

Kartal, B. and A. Kaplan. 2005. Leaf, stem anatomy and polen morphology of Quercus cerris L. and Quercus ilex L. in Zonguldak, Turkey. Master Thesis, Zonguldak.

Lersten, N.R. and H.T. Jr. Horner. 2000. Calcium oxalate crystal types and trends in their distribution patterns in leaves of Prunus (Rosaceae: Prunideae). Plant Syst. Evol. 224: 83-96.

Tian, H.Q., A. Kuang, E.M. Musgrave and S.D. Russle. 1998. Calcium distribution in fertile and sterile anthers of a photoperiod-sensitive genic male-sterile rice. Planta 204: 183-192.

Yasue T. 1969. Histochemical identification of calcium oxalate. Acta Histochem. Cytochem. 2: 83-95.

(Manuscript received on 17 December, 2008; revised on 12 February, 2009) 